\section{BUSINESS GEOGRAPHICS}

FOR EDUCATORS AND

RESEARCHERS -

\section{MAY 1996 PROCEEDINGS}

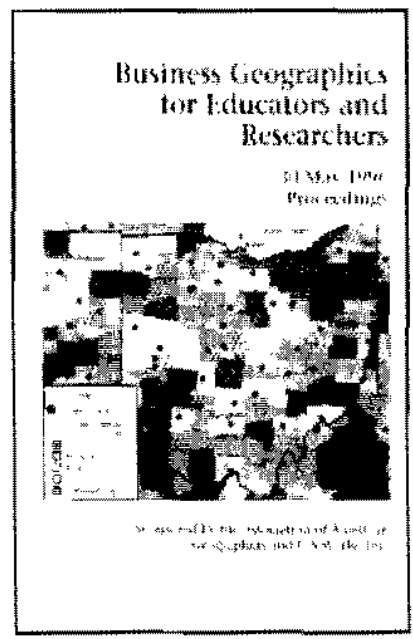

de Association of American Geographers a Gis World, Inc. (org.).

Washington: Association of American Geographers, 1996 , $207 \mathrm{p}$.

por Francisco Aranha, professor do Departamento de Métodos Quantitativos da EAESP/FGV e consultor de empresas. E-mail: laranha 9 ibm.net

partir do mês de julho de 1997, passou a fazer parte do acervo da Biblioteca Karl A. Boedecker da EAESP/FGV, um exemplar dos Anais da Conferência de Maio de 96 para Educadores e Pesquisadores em Geografia Empresarial (Business Geographics).

Esta disciplina, que trata de problemas empresariais em que a localizaçẫo dos fenômenos é fator determinante das soluçôes, tem passado por grandes transformaçoes nos últimos anos, principalmente em decorrência da disseminação dos recursos computacionais dos Sistemas de Informaçôes Geográficas (SIG, ou GIS, em inglês); do barateamento dos microcomputadores e aumento de sua capacidade de processamento e armazenamento de dados; e da disponibilização de bases de dados geográficos em meio magnético.

Apesar da aguda necessidade de troca de experiências educacionais em relação aos Sistemas de Informaçoes Geografficas aplicados à Administração de Empresas, poucos congressos foram realizados sobre o tema e, pela primeira vez, os trabalhos discutidos em uma conferência säo publicados. Trata-se, portanto, de um dos raros livros disponiveis na área.

Os anais reúnem 21 artigos de professores e alunos de universidades americanas e canadenses, e podem, grosso modo, ser agrupados em três categorias:

- relatos do desenvolvimento da disciplina de $S 1 G$ em faculdades de Geografia:

- relatos de aplicações práticas de SIG em diversos ramos empresariais:

- relatos da inclusão do assunto no currículo de graduação e pós-graduação de Escolas de Administração de Empresas.

De particular interesse para a comunidade da EAESP/FGV são os cinco artigos com depoimentos dos professores de escolas de Administração da Universidade Estadual da Califómia, Universidade de Missouri, Universidade Estadual de Connecticut do Sul, Universidade de Indiana, Universidade de Redlands e Universidade Estadual da Flórida.

Estes trabalhos convergem para o seguinte diagnóstico:

1. O ensino de aplicações de SIG em Administração e a publicação de trabalhos sobre o tema não refletem a importância $e$ a atenção que lhes tem sido atribuída pelas empresas.

2. De um lado, esta sub-representaçẫo acadêmica de conhecimentos cada vez mais requisitados pelo mercado de trabalho tem raiz no sigilo que envolve o desenvolvimento de aplicaçoses de SIG nas empresas, por considerarem-nas fonte de poderosas vantagens competitivas.

3. De outro lado, a sub-representação decorre de um desconfortável posicionamento da disciplina dentro da estrutura geralmente departamentalizada das escolas. Como o assunto é indiscutivelmente interdisciplinar, envolvendo pelo menos as áreas de Marketing, Produção, Métodos Quantitativos, Informática e Geografia, ou fica óffão, sem um responsável claro pelo seu desenvolvimento na instituiçâo, ou, mais provavelmente. é objeto de uma disputa imobilizante dos departamentos pela "posse" da disciplina. 
4. Entre as dificuldades enfrentadas na introdução da disciplina nos currículos estão:

- o alto custo do hardware e software necessários;

- a necessidade de uma equipe que forneça suporte técnico de informática a alunos e professores;

- a escassez de dados censitários, econômicos e empresariais relevantes;

- a escassez de material didático e de livros de apoio;

- o relativo desconhecimento dos alunos e professores sobre o assunto, provocando baixa oferta e demanda de cursos:

- a falta de tradição dos currículos, exigindo maior risco por parte dos professores que implantam o curso.

5. A tendência é a disciplina consolidar-se e expandir-se nos cursos de Administraçâo por duas razôes básicas:

- os resultados obtidos pelas empresas que utilizam a tecnologia de SIG têm sido muito positivos; em decorrência disso,

- a comunidade empresarial tem apresentado uma demanda crescente por profissionais capazes de utilizar esta ferramenta.

Os cinco papers em destaque sugerem uma estratégia básica para se superar as dificuldades encontradas pelas escolas na implantação de disciplinas que utilizem SIG: a integraçâa de esforços e recursos, internos e externos.

De um lado, deve-se procurar uma abordagem interdisciplinar. Uma sugestăo muito razoável é iniciar a utilização de SIG em disciplinas de Estudos de Mercado. que necessariamente envolvem aspectos de Planejamento Estratégico, Economia, Marketing, Mêtodos Quantitativos. Informática, Logística e outras áreas; num segundo momento, mesmo disciplinas não tăo evidentemente conexas, como, por exemplo, Cultura Organizacional, podem ser englobadas neste esforço aglutinador.

De outro lado, deve-se buscar uma integração com a comunidade; se as escolas se dispóem a prestar serviços à sociedade, encontram recursos para o seu aparelhamento. Assim. sugere-se a procura ativa de parceiros na iniciativa privada, principalmente entre potenciais usuários da metodologia e fornecedores de software e equipamentos; e, no setor público, entre detentores de importantes bases de dados e também. naturalmente, entre potenciais usuários.

Como exemplo de resultados concretos nessa linha de envolvimento com a comunidade, professores da Universidade de Western Washington descrevem o convênio firmado com a prefeitura local.

A prefeitura comprometeu-se a disponibilizar bases de dados mobiliárias, demogrăficas, econômicas e ambientais, e a fornecer os recursos necessários para que a universidade comprasse o equipamento e o software de SIG necessários e treinasse seu pessoal: em contrapartida, a universidade responsabilizon-se por abrigar as instalações, gerenciar o departamento e disponibilizar à prefeitura o uso remoto do sistema. Juntas, comprometeram-se a administrar o desenvolvimento do projeto, a realizar eventos públicos para incentivar a comunidade, inclusive empresarial, a utilizar os dados disponibilizados e a buscar novos convênios com outras instituiçôes detentoras de bases de dados.

Os papers ainda sugerem conteúdos curriculares e estratégias de abordagem, apontam fases de implementaçẫo dos cursos e relatam sucessos e fracassos em suas iniciativas. Esse conjunto de experiências acumuladas representam, portanto, um grande potencial de economia de esforços para as escolas que planejam incorporar o tema ao seu repertório.

Os artigos sobre casos práticos são bastante diversificados nos temas, abrangendo desde uma pesquisa, muito informativa, sobre a utilizaçăo de SIG em 52 empresas americanas até o registro do creseimento do comércio varejista na Estônia. Apesar do conjunto ser heterogêneo quanto à qualidade do material apresentado, sua leitura ê, em geral, interessante e informativa. Em particular, o artigo da Universidade do Tennessee sobre aplicaçoes existentes e potenciais em logística será bastante útil para pro. fessores e pesquisadores da área.

Nos trabalhos dos professores de escolas de Geografia chamam a atenção duas constataçôes: o crescimento da importância dos SIG (de um curso de um semestre na Universidade Politécnica de Ryerson, em Toronto, a disciplina ampliou-se para um curso de oito semestres); e os esforços destas escolas, quando institutos membros de universidades, em atender um público cada vez mais diversificado, no qual se destacam alunos das escolas de administração pública e privada.

Considerando-se que a EAESP recebeu recentemente uma grande doação de software de SIG, contando agora com um laboratório completamente equipado, a leitura dos Anais da Conferência para Educadores e Pesquisadores em Geografia Empresarial é extremamente oportuna, devendo auxiliar os professores que estão pretendendo incorporar a ferramenta as suas disciplinas e mestrandos e doutorandos em busca de temas relevantes para suas dissertaçôes e teses. 